\title{
Comparison of Corrosion Behavior of Electrochemically Deposited Nano-Cobalt-Coated Ni Sheet
}

\author{
Nasser Al-Aqeeli and Ihsan-ul-Haq Toor \\ Deptartment of Mechanical Engineering, King Fahd University of Petroleum and Minerals (KFUPM), Dhahran 31261, Saudi Arabia \\ Correspondence should be addressed to Ihsan-ul-Haq Toor; ihsan@kfupm.edu.sa
}

Received 24 February 2013; Revised 21 August 2013; Accepted 21 August 2013

Academic Editor: Pier P. Piras

Copyright (C) 2013 N. Al-Aqeeli and I.-u.-H. Toor. This is an open access article distributed under the Creative Commons Attribution License, which permits unrestricted use, distribution, and reproduction in any medium, provided the original work is properly cited.

\begin{abstract}
Corrosion behavior of nano-coblat-coated Ni sheet was compared with pure $\mathrm{Ni}$ and $20 \% \mathrm{Fe}-\mathrm{Ni}$ alloy sheet using potentiodynamic polarization and linear polarization technique in $0.1 \mathrm{M} \mathrm{NaCl}$ solution at room temperature. Results showed that corrosion resistance properties of nano-Co-coated Ni sheet were almost same as that of pure Ni sheet, however corrosion resistance of $20 \% \mathrm{Fe}-\mathrm{Ni}$ sheet was decreased significantly. Pitting potential of $20 \% \mathrm{Fe}-\mathrm{Ni}$ sheet was subsequently decreased as compared to pure Ni sheet as well as nano-cobalt-coated Ni sheet. SEM/EDS analysis of the corroded surfaces showed that both pure Ni and nano-coblat-coated Ni sheet did not show any appreciable corrosion however significant corrosion was observed in the case of $20 \% \mathrm{Fe}-\mathrm{Ni}$ sheet.
\end{abstract}

\section{Introduction}

Among different alloys used for coating applications, Nibased alloys are very successful owing to their remarkable mechanical, adhesion, tribological, and corrosion properties as well as good thermal stability. Cobalt, as an alloying element in Ni-base alloys, is considered to contribute in many different ways, in improving their properties [1] and also these alloys can be prepared using simple methods such as electrodeposition technique. This method can be used in the development of $\mathrm{Ni}$-Co nanostructured coatings with improved properties. It is preferred because it is scalable, can easily overcome shape limitations, is economically viable, and produces pores-free and high purity nanostructures [2].

There have been few investigations on binary Ni-Co systems along with ternary additions, such as oxides [3, 4], nitrides [1, 5], carbides [6-8], and carbon nanotubes [9]. Some researchers also successfully produced Ni-Co nanowires [10]. However, there are not many investigations on the corrosion performance of such alloys and possible ways to improve their performance in variety of environments. For example a lot of work has been done and still being done to understand the corrosion behavior of passive metals by investigating the passive films formed on their surface at nanoscale. Passive films found in Fe-Cr alloys and high-speed steels show superior resistance than carbon steels because of the presence of spheroidal nanoparticles of $\sim 40 \mathrm{~nm}[11,12]$. Same has been reported for many other alloys such as for Al-Mg alloys; it has been found that the nanoprecipitates of $\mathrm{Al}_{3} \mathrm{SiC}$ can significantly affect the passivity of these alloys $[13,14]$. Also thermally sprayed coatings of stainless steel, nickel, and nickel alloys are being used to maximize the corrosion resistance. It is clearly observed from the extensive studies on steels and Ni-based alloys that the best corrosion resistance was found on nickel with small particle size of 16$44 \mathrm{um}$.

With coatings on microscale, pitting and erosion-corrosion is a serious issue, and it is expected that if a nanocrystalline coating of nickel is applied, even a higher resistance to corrosion can be achieved [15]. Nano-sized $\beta \mathrm{Ni}(\mathrm{OH})_{2}$ electrolyte exhibits an excellent electrochemical performance which is markedly superior to spherical $\beta \mathrm{Ni}(\mathrm{OH})_{2}[16]$. It has been reported that electrodeposited amorphous alloys has better corrosion resistance and amorphous $\mathrm{Ni}$-Co-based alloy which showed better pitting corrosion resistance [17]. In $\mathrm{Ni}$-Co-P amorphous alloy system, presence of Co showed a significant effect in improving the corrosion resistance of the alloy [18] and another study suggested that nanostructured 
TABLE 1: Chemical composition of bath used for electrodeposition of nano Co-coated $\mathrm{Ni}$ sheet.

\begin{tabular}{lc}
\hline Chemical Addition & Amount $(\mathrm{g} / \mathrm{L})$ \\
\hline $\mathrm{CoSO}_{4} \cdot 7 \mathrm{H}_{2} \mathrm{O}$ & 30 \\
$\mathrm{H}_{3} \mathrm{BO}_{3}$ & 15 \\
$\mathrm{NaCl}$ & 10
\end{tabular}

electrodeposited Co and Co-P alloy can improve the corrosion behavior significantly [19].

Therefore, it is an important area of investigation, and the objective of this study was to investigate the corrosion behavior of electrodeposited nano-Cobalt-coated $\mathrm{Ni}$ sheet, pure $\mathrm{Ni}$ foil, and $20 \% \mathrm{Fe}-\mathrm{Ni}$ in terms of corrosion rate values as well polarization resistance $\left(R_{p}\right)$.

\section{Experimental Details}

Three different materials, that is, pure Ni, nano-cobalt coated $\mathrm{Ni}$, and $20 \% \mathrm{Fe}-\mathrm{Ni}$, have been investigated for their corrosion performance during this study. The followings are the details of different techniques used for material preparation as well as electrochemical investigations.

2.1. Material Preparation. Nano-Co-coated Ni sheets were prepared with electrodeposition technique using different applied currents densities and additives in the deposition path. The bath temperature was maintained at $35^{\circ} \mathrm{C}$, and electrolyte-containing beaker was placed for about $20 \mathrm{~min}$ utes in the bath before testing, to assure thermal equilibrium. A magnetic stirrer was operated throughout the process to facilitate dispersion of the electrolyte. Two anodes were used consisting of $99.95 \%$ Co and $99.95 \%$ Ni. Table 1 shows the base composition of the bath used in these experiments to prepare nano-coblat-coated $\mathrm{Ni}$ sheet.

The $\mathrm{pH}$ measurements were constantly performed using a calibrated digital $\mathrm{pH}$ (meter). Pulsed current was used in order to avoid any stress buildup in the coatings as well as to promote the nucleation of grains. Duty cycle was fixed at 50\% (pulse on time and off time was set to $5 \mathrm{~ms}$ ). Bath composition (Table 1) was used with an average current density $\sim 2 \mathrm{~A} / \mathrm{dm}^{2}$. A well-polished $\mathrm{Ni}$ cathode was used for depositing the nanoCo film to prepare nano-coblat-coated Ni sheet.

2.2. Electrochemical Investigations. Potentiodynamic polarization along with linear polarization technique was used to evaluate the corrosion performance of the prepared coatings. Experiments were carried out in a three electrode flat cell (K0235, Princeton Applied Research). An Ag/ AgCl electrode was used as a reference electrode, and counter electrode was made of platinum. The investigations were carried out with an exposed working electrode area of $1 \mathrm{~cm}^{2}$ in $0.1 \mathrm{M} \mathrm{NaCl}$ solution at room temperature. Specimens were degreased in benzene and cleaned ultrasonically in DI water prior to electrochemical experiments. The experiments were performed using PCI4/750 Gamry potentiostat and repeated several

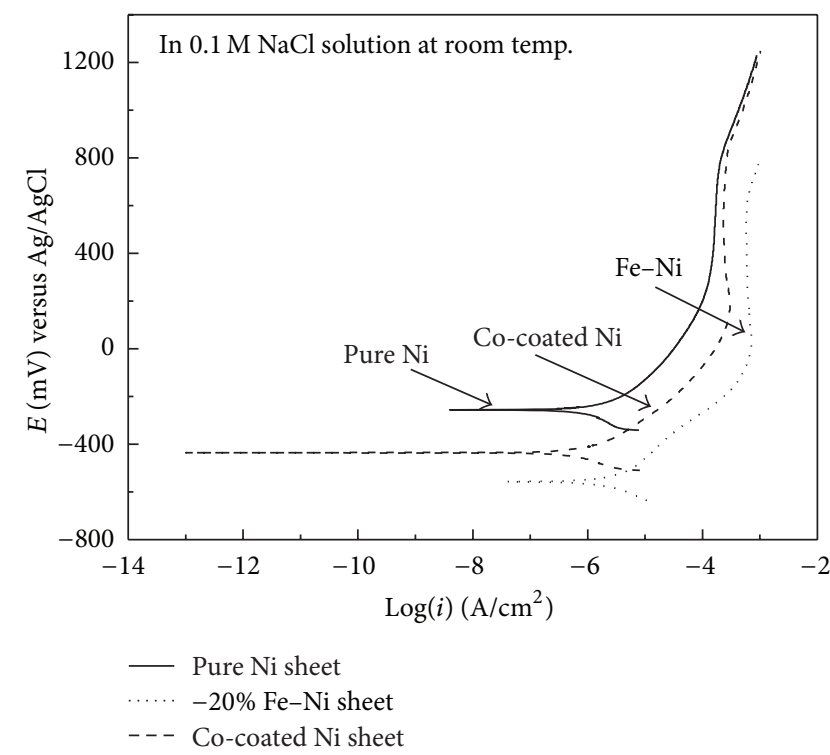

FIGURE 1: Potentiodynamic polarization response of the alloys in $0.1 \mathrm{M} \mathrm{NaCl}$ solution at room temperature.

times to ensure the reproducibility of the data. DC105 corrosion software was used to analyze the data, and polarization experiments were performed at a scan rate of $0.1 \mathrm{mV} / \mathrm{s}$ to measure the polarization resistance values (potentials were $-20 \mathrm{mV}$ and $+20 \mathrm{mV}$ versus open circuit corrosion potential (OCP)). SEM/EDS analysis was carried out after corrosion tests to investigate the chemical composition of corrosion products and their morphology.

\section{Results and Discussion}

3.1. Potentiodynamic Polarization Response of the Alloys. Figure 1 shows the potentiodynamic polarization response of the three alloys in $0.1 \mathrm{M} \mathrm{NaCl}$ solution at room temperature. Pitting potential $\left(E_{\mathrm{pit}}\right)$ value was taken at the potential, where there was a sudden and substantial increase in corrosion current density of the alloys. Overall all the alloys showed a stable passive range; however at higher potentials current has started to increase slowly. So those critical points were taken as pitting potential of the alloys. It was found that pitting potential was almost similar for pure $\mathrm{Ni}$ sheet and that of nano-Co-coated $\mathrm{Ni}$ sheet, that is, $1560 \mathrm{mV}_{\mathrm{Ag} / \mathrm{AgCl}}$, followed by $20 \% \mathrm{Fe}-\mathrm{Ni}$ sheet, which was the lowest, that is, $798 \mathrm{mV}_{\mathrm{Ag} / \mathrm{AgCl}}$. Evidently, pure Ni sheet and nano-Co-coated $\mathrm{Ni}$ sheet exhibited higher resistance to localized corrosion as compared to $20 \% \mathrm{Fe}-\mathrm{Ni}$ in terms of pitting potential. These results demonstrate that the resistance to pitting corrosion or the pitting potential of the alloys was not affected affected by coating with nano-Cobalt alloy; rather it performed almost similar to that of pure Ni alloy. However the addition of iron decreased the corrosion resistance.

The corrosion potential of pure Ni sheet is higher than rest of the alloys $(\mathrm{Ni}$ sheet $=-256>$ nano-Co-coated $\mathrm{Ni}$ sheet $=-436>20 \% \mathrm{Fe}-\mathrm{Ni}=-557) \mathrm{mV}_{\mathrm{Ag} / \mathrm{AgCl}}$, respectively. These results are in agreement with already reported findings 


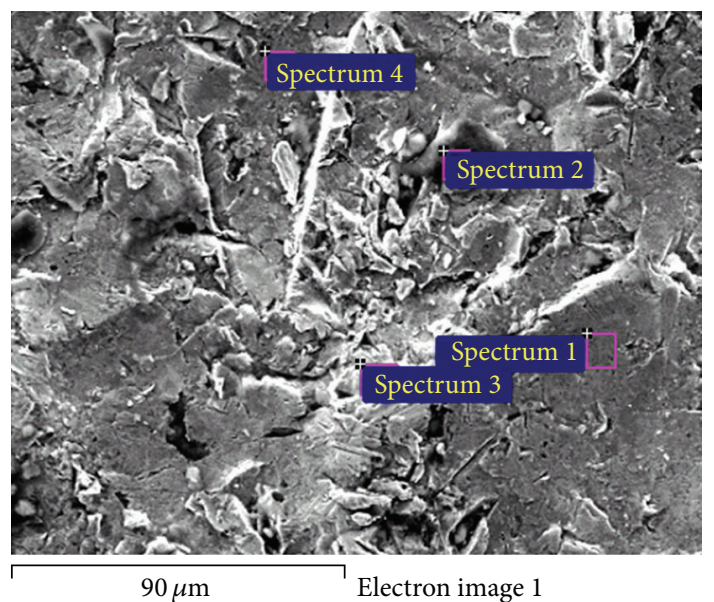

\begin{tabular}{|c|c|c|c|c|}
\hline Spectrum & $\mathrm{C}$ & $\mathrm{O}$ & $\mathrm{Ni}$ & Total \\
\hline Spectrum 1 & 1.22 & 1.57 & 97.21 & 100 \\
\hline Spectrum 2 & 6.64 & 5.28 & 88.08 & 100 \\
\hline Spectrum 3 & 1.89 & 1.61 & 96.5 & 100 \\
\hline Spectrum 4 & 1.17 & 1.54 & 97.29 & 100 \\
\hline
\end{tabular}

FIGURE 2: SEM/EDS of the pure Ni sheet after corrosion tests in $0.1 \mathrm{M} \mathrm{NaCl}$ temperature.

that corrosion potential of materials is related with $\mathrm{Ni}$ content of the alloys. As $\mathrm{Ni}$ is a noble element and hence will increase the corrosion potential, as shown in Figure 1 [20]. The stage of pitting includes passive film breakdown, metastable pitting, initiation and repassivation, and stable pit growth. The metastable pitting stage is thought to be the most important stage because only pits that survive this stage could become stable growing pits. Comparison of the passive current density showed similar trend observed for pitting potential. Passive current density of pure $\mathrm{Ni}$ and that of nanoCo-coated Ni sheet was almost similar. However the addition of iron increased the passive current density of $20 \% \mathrm{Fe}-\mathrm{Ni}$ sheet, suggesting a less stable and less protective film on this alloy as compared to rest of the alloys.

These results of potentiodynamic polarization were further confirmed by polarization resistance experiments in Section 3.2.

3.2. Comparison of the Polarization Resistance. Linear polarization resistance experiments were performed for all three samples, that is, pure $\mathrm{Ni}$ sheet, $20 \% \mathrm{Fe}-\mathrm{Ni}$, and nano-Cocoated $\mathrm{Ni}$ sheet, and subsequently data was analyzed. Table 2 showed the polarization resistance $\left(R_{p}\right)$ as well as corrosion rate values of these specimens.

It is clear from the results presented in Table 2 that pure $\mathrm{Ni}$ has the highest corrosion resistance in $0.1 \mathrm{M} \mathrm{NaCl}$ solutions, having polarization resistance $\left(R_{p}\right)$ value of $106.9 \mathrm{~K} \Omega$. It was followed by nano-Co-coated Ni-sheet with $R_{p}$ value of $102.6 \mathrm{~K} \Omega$ and $34.2 \mathrm{~K} \Omega$ for $20 \% \mathrm{Fe}-\mathrm{Ni}$ foil, respectively. The comparison of corrosion rate values showed that both the pure Ni sheet and nano-Co-coated sheet have very similar
TABLE 2: Comparison of polarization resistance and corrosion rate of three samples after corrosion tests in $0.1 \mathrm{M} \mathrm{NaCl}$ solution.

\begin{tabular}{lcc}
\hline Materials & $\begin{array}{c}\text { Polarization } \\
\text { Resistance }(\mathrm{K} \Omega)\end{array}$ & $\begin{array}{c}\text { Corrosion } \\
\text { Rate }(\mathrm{mmpy})\end{array}$ \\
\hline 20\% Fe-Ni sheet & 34.26 & 0.3 \\
Pure Ni sheet & 106.9 & 0.003 \\
Nano-Cobalt coated Ni sheet & 102.6 & 0.003 \\
\hline
\end{tabular}

corrosion resistance, that is, $0.003 \mathrm{mmpy}$ for both of the above materials. However 20\% Fe-Ni foil showed high corrosion rate value, that is, $0.3 \mathrm{mmpy}$ as compared to the other two materials.

These results suggest that nano-Co-coating of a $\mathrm{Ni}$ sheet did not decrease the corrosion resistance properties of pure $\mathrm{Ni}$, while addition of iron in $\mathrm{Ni}$ decreased its corrosion resistance properties as compared to pure $\mathrm{Ni}$ and nano-Cocoated $\mathrm{Ni}$ sheet. These results can be further confirmed based on SEM/EDS analysis of the specimens after corrosion tests.

Figure 2 shows the surface of pure Ni sheet after electrochemical corrosion tests in $0.1 \mathrm{M} \mathrm{NaCl}$ solution. The $\mathrm{Ni}$ sheet looks in very good shape and there is no visible degradation as can be confirmed from SEM image. EDS data presented in Figure 2, showed that composition of the surface remains almost same at all locations. Some oxides of nickel are present; however Nickel oxides are good considering their corrosion resistance behavior. It has been reported $[21,22]$ that the passive film on $\mathrm{Ni}$ composed of duplex layered structure with the inner $\mathrm{NiO}$ and outer $\mathrm{Ni}(\mathrm{OH})_{2}$ which contribute in improving the corrosion resistance properties. $\mathrm{Ni}$ is not only an important austenite stabilizing element in stainless steels, but also has effects on the corrosion resistance of the alloy. It is known that $\mathrm{Ni}$ can lower the critical current density and elevate the pitting potential of austenitic alloys. Stress corrosion cracking susceptibility of Fe-Cr-Ni alloy is significantly dependent on $\mathrm{Ni}$ content. The photocurrent spectra for the passive films formed on Fe-20Cr-15Ni alloys showed very similar behavior to that for the passive film on $\mathrm{Fe}-20 \mathrm{Cr}$ at low photon energy region below $5 \mathrm{eV}$, showing that the base structure of the passive films formed on Fe$20 \mathrm{Cr}-15 \mathrm{Ni}$ was found to be $\mathrm{Cr}$-substituted $\gamma-\mathrm{Fe}_{2} \mathrm{O}_{3}$. However, the photocurrent spectra for the passive films formed on $\mathrm{Fe}$ 20Cr-15Ni exhibited additional spectral components induced by $\mathrm{Ni}$ oxide $(\mathrm{NiO})$. Regardless of the composition of alloys, the Mott-Schottky plots for the passive films showed $n$-type semiconductivity with shallow and deep donors, which are associated with oxygen vacancy and $\mathrm{Cr}^{6+}$ ions, respectively. Comparing with the passive film of $\mathrm{Fe}-20 \mathrm{Cr}$, the density of shallow donor was decreased by addition of $\mathrm{Ni}$ and density deep donor was increased, which means corrosion resistance properties were increased considerably, due to incorporation of $\mathrm{Ni}^{2+}$ by substituting $\mathrm{Fe}^{3+}$ in spinel structure of $\gamma-\mathrm{Fe}_{2} \mathrm{O}_{3}$.

Figure 3 shows the SEM/EDS of the nano-Co-coated Ni sheet after the corrosion tests. It is to be emphasized that $\mathrm{Co}$ is very intact on the Ni sheet and no significant damage is caused by the corrosion tests under given conditions. Cobalt was above $90 \%$ on all areas on the surface. Some oxidation 


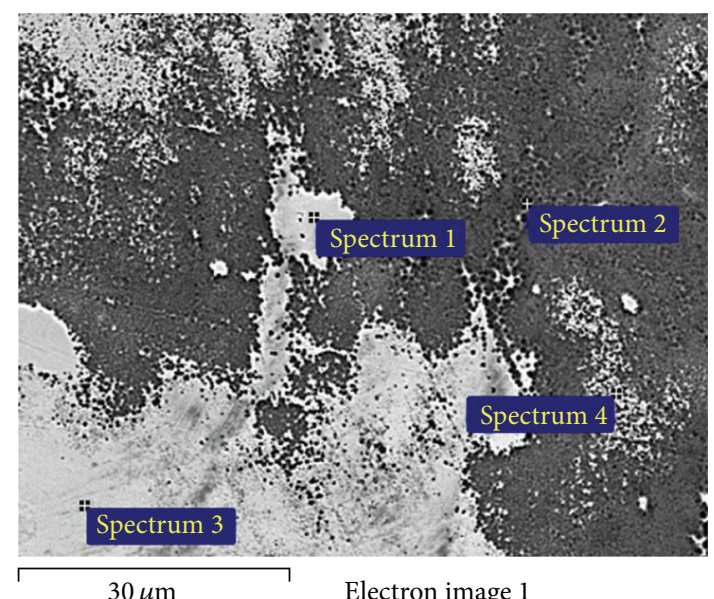

\begin{tabular}{|l|l|l|l|l|}
\hline Spectrum & C & O & Co & Total \\
\hline Spectrum 1 & 0.27 & & 99.73 & 100 \\
\hline Spectrum 2 & 1.82 & 6.96 & 91.22 & 100 \\
\hline Spectrum 3 & 0.28 & & 99.72 & 100 \\
\hline Spectrum 4 & 0.62 & 6.07 & 93.31 & 100 \\
\hline
\end{tabular}

FIGURE 3: SEM/EDS of the nano-Co-coated Ni sheet after corrosion tests in $0.1 \mathrm{M} \mathrm{NaCl}$ solution.

occurred; however cobalt oxide has good corrosion resistant materials [21, 22]. Also it appears that there might be some randomly distributed metastable sort of pits, which died away by repassivation, and surface is almost completely covered with cobalt coating [23].

Figures $4(\mathrm{a})$ and $4(\mathrm{~b})$ show the SEM/EDS of $20 \% \mathrm{Fe}$ $\mathrm{Ni}$ foil after corrosion tests. Significant corrosion has been observed at different locations and it was mainly iron oxide. It is clear from Figure 4(b) that pits were interconnected, which has increased the corrosion rate/dissolution rate of this coating. These results are in agreement with those presented in Section 3.2, where it was concluded that pure Ni and nanoCo-coated Ni sheet both exhibited good corrosion resistance properties. However the induction of $\mathrm{Fe}$ in $\mathrm{Ni}$ decreased the corrosion resistance properties as was clear from Figure 4.

Another important comparison is of free corrosion potential, and it was found from Figure 1 that nano-Cocoated $\mathrm{Ni}$ sheet has the lowest $E_{\text {corr }}(-0.48 \mathrm{~V} \mathrm{SCE})$, followed by $20 \% \mathrm{Fe}-\mathrm{Ni}$ sheet $(-0.38 \mathrm{~V} \mathrm{SCE})$ and pure Ni sheet $(-0.20 \mathrm{~V}$ SCE), respectively. Similar results have been reported previously by Aledresse and Alfantazi [24], and they observed the $E_{\text {corr }}$; for nanocrystalline Co $\left(-0.574 \mathrm{~V}_{\mathrm{Ag} / \mathrm{AgCl}}\right)$ specimen was more cathodic than that of the conventional polycrystalline $\mathrm{Co}$, which was in contrast to the nanocrystalline pure $\mathrm{Ni}$ system studied by Rofagha et al. [25]. The authors [25] reported that there is a significant anodic shift in $E_{\text {corr }}$ for the nanocrystalline $\mathrm{Ni}$ with respect to its conventional crystalline counterpart. This was interpreted to be the result of the enhanced catalysis of the hydrogen reduction reaction at the surface of nanocrystalline $\mathrm{Ni}$ due to the large quantity of intercrystalline defects such as grain boundaries and triple

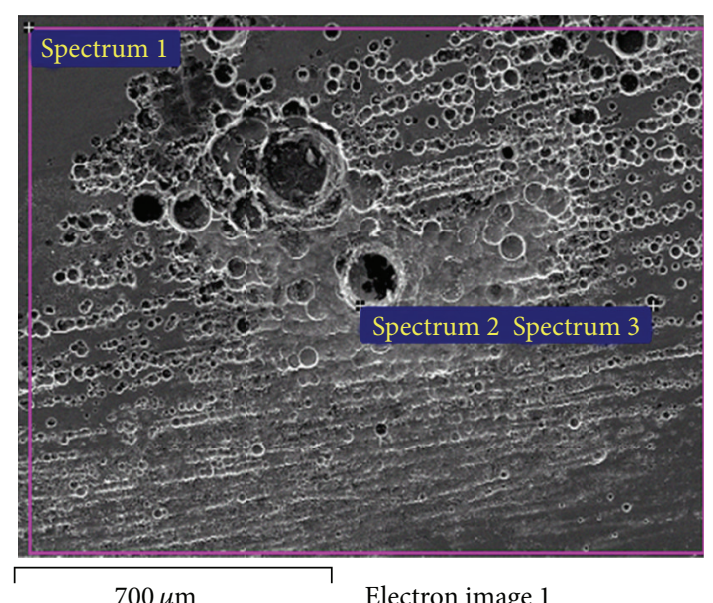

\begin{tabular}{|c|c|c|c|c|c|}
\hline Spectrum & $\mathrm{C}$ & $\mathrm{O}$ & $\mathrm{Fe}$ & $\mathrm{Ni}$ & Total \\
\hline Spectrum 1 & 1.07 & 4.99 & 21.08 & 72.86 & 100 \\
\hline Spectrum 2 & 1.05 & 9.59 & 18.38 & 70.98 & 100 \\
\hline Spectrum 3 & 1.57 & 5.46 & 20.75 & 72.22 & 100 \\
\hline
\end{tabular}

(a)

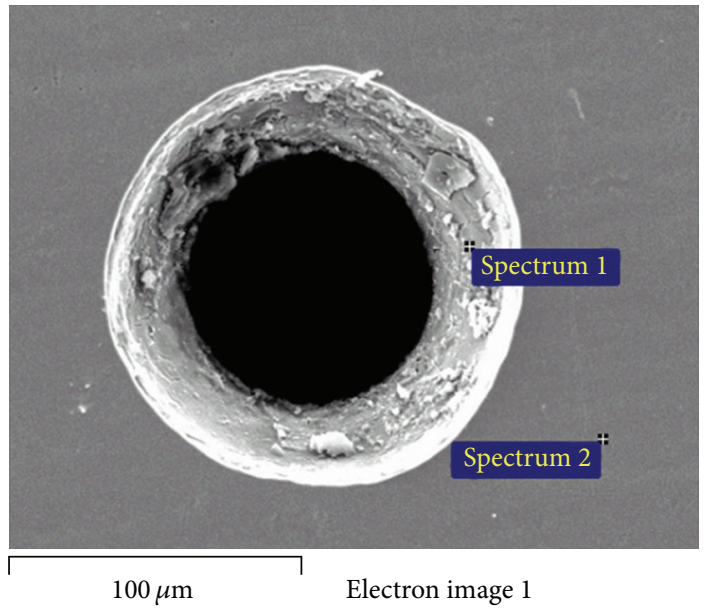

\begin{tabular}{|c|c|c|c|c|c|}
\hline Spectrum & $\mathrm{C}$ & $\mathrm{O}$ & $\mathrm{Fe}$ & $\mathrm{Ni}$ & Total \\
\hline Spectrum 1 & 1.54 & 18.32 & 19.69 & 60.46 & 100 \\
\hline Spectrum 2 & 0.39 & & 22.75 & 76.85 & 100 \\
\hline
\end{tabular}

(b)

FIGURE 4: (a) SEM/EDS of the 20\% Fe-Ni sheet after corrosion tests in $0.1 \mathrm{M} 1 \mathrm{M} \mathrm{NaCl}$ solution and (b) SEM/EDS of pit morphology and composition in $20 \% \mathrm{Fe}-\mathrm{Ni}$ sheet after corrosion tests in $0.1 \mathrm{M} \mathrm{NaCl}$.

junctions. This inconsistency is probably due to the difference in crystalline structure between $\mathrm{Ni}$ and Co. Like many other transition metals, the cobalt surface is covered by a native barrier film, which consists mainly of $\mathrm{CoO}$ or hydrated oxide $\mathrm{CoOH}_{2} \mathrm{O}$ [26]. Indeed, the potentiodynamic polarization of the polycrystalline cobalt and cobalt-based alloys has been reported on numerous occasions. For example, Badawy et 
al. [27] studied the anodic polarization of the conventional cobalt in acidic, neutral, and alkaline solutions. They considered that in acidic solutions, the passive film is unstable, and hence higher rates of corrosion were recorded. This corrosion process is preceded by a pure chemical dissolution of the native cobalt oxide $(\mathrm{CoO})$ or the hydrated oxide $\left(\mathrm{CoOH}_{2} \mathrm{O}\right)$. There are no significant differences between the chemical compositions of the nanocrystalline and polycrystalline Co, so it can be speculated that the cathodic shift of nanocrystalline Co may be due to the microstructural differences (i.e., intercrystalline volume fraction) between the nanocrystalline and conventional polycrystalline Co. In the low potential region, corrosion attack is initiated more easily at defects sites (i.e., grain boundaries and triple junctions). The higher volume fraction of the intercrystalline constituent in nanocrystalline materials provides active sites due to the fact that grain boundaries and triple junctions possess higher energies than the crystal surface.

So based on above discussions and experimental results presented, it can be suggested that electrochemically deposited nano-Co coatings can be very useful in improving the corrosion performance, and results here have shown that their performance was almost similar to that of pure $\mathrm{Ni}$ sheet. On the other hand, iron in an alloy will degrade the corrosion performance.

\section{Conclusions}

Results of this work can be concluded as follows:

(1) Both pure Ni sheet and nano Co-coated Ni sheet exhibited very good corrosion resistance properties measured in terms of pitting potential $\left(E_{\text {pit }}\right)$ and polarization resistance $\left(R_{p}\right)$.

(2) Corrosion resistance of $20 \% \mathrm{Fe}-\mathrm{Ni}$ sheet was decreased significantly as many pits appeared after corrosion tests.

(3) SEM/EDX analysis showed no appreciable corrosion of pure Ni sheet as well as of nano-Co-coated Ni sheet; however 20\% Fe-Ni exhibited significant corrosion.

\section{Acknowledgments}

The authors gratefully acknowledge the support provided by King Fahd University of Petroleum \& Minerals (KFUPM), Saudi Arabia, under the research Grant no. IN111048 for conducting this research.

\section{References}

[1] L. Shi, C. Sun, F. Zhou, and W. Liu, "Electrodeposited nickelcobalt composite coating containing nano-sized $\mathrm{Si}_{3} \mathrm{~N}_{4}$," Materials Science and Engineering A, vol. 397, no. 1-2, pp. 190-194, 2005.

[2] I. Gurrappa and L. Binder, "Focus on recent breakthroughs in materials science and technology," Science and Technology of Advanced Materials, vol. 9, no. 1, 2008.

[3] L. Chang, M. An, H. Guo, and S. Shi, "Microstructure and properties of $\mathrm{Ni}-\mathrm{Co} /$ nano- $-\mathrm{Al}_{2} \mathrm{O}_{3}$ composite coatings by pulse reversal current electrodeposition," Applied Surface Science, vol. 253, no. 4, pp. 2132-2137, 2006.

[4] S.-T. Oh, M. Sando, and K. Niihara, "Processing and properties of Ni-Co alloy dispersed $\mathrm{Al}_{2} \mathrm{O}_{3}$ nanocomposites," Scripta Materialia, vol. 39, no. 10, pp. 1413-1418, 1998.

[5] C. Wang and K. Chan, Materials Science and Engineering.

[6] M. Srivastava, V. Grips, and K. Rajam, "Electrochemical deposition and tribological behaviour of $\mathrm{Ni}$ and $\mathrm{Ni}$-Co metal matrix composites with SiC nano-particles," Applied Surface Science, vol. 253, no. 8, pp. 3814-3824, 2007.

[7] L. Shi, C. Sun, P. Gao, F. Zhou, and W. Liu, "Mechanical properties and wear and corrosion resistance of electrodeposited Ni$\mathrm{Co} / \mathrm{SiC}$ nanocomposite coating," Applied Surface Science, vol. 252, no. 10, pp. 3591-3599, 2006.

[8] Y. Wang and Z. Xu, "Nanostructured Ni-WC-Co composite coatings fabricated by electrophoretic deposition," Surface and Coatings Technology, vol. 200, no. 12-13, pp. 3896-3902, 2006.

[9] L. Shi, C. Sun, P. Gao, F. Zhou, and W. Liu, "Electrodeposition and characterization of Ni-Co-carbon nanotubes composite coatings," Surface and Coatings Technology, vol. 200, no. 16-17, pp. 4870-4875, 2006.

[10] C. Garcia, P. Lecante, B. Warot-Fonrose, D. Neumeyer, and M. Verelst, "Electrochemical synthesis of cobalt nickel nanowires in an ethanol-water bath," Materials Letters, vol. 62, no. 14, pp. 2110-2113, 2008.

[11] V. A. Alves, C. M. Brett, and A. Caveleiro, "Influence of heat treatment on the corrosion of high speed steel," Journal of Applied Electrochemistry, vol. 31, no. 1, pp. 65-72, 2001.

[12] V. A. Alves, C. M. Brett, and A. Caveleiro, "Influência da composição e do tratamento térmico na corrosão por picadas de aços," Revista Corrosão e Protecção de Materiais, vol. 20, no. $17,2001$.

[13] M. K. Cavanngh, N. Berbillis, R. G. Buchhelt, and F. Boratd, "Weld metal microstructural characteristics in pulsed Nd: YAG laser welding," Scripta Materilia, vol. 56, no. 11, pp. 955-958, 2007.

[14] M. E. Van Dalen, D. C. Dunand, and D. N. Seidman, "Effects of Ti additions on the nanostructure and creep properties of precipitation-strengthened Al-Sc alloys," Acta Materialia, vol. 53, no. 15, pp. 4225-4235, 2005.

[15] "A. J. Sturgeon and D. Buxton: The electrochemical behaviour of HVOF sprayed coatings," in Thermal Spray-Surface Engineering Via Applied Research, C. C. Berndt, Ed., ASM International, 2000.

[16] H. Zhu, S. G. Yang, G. Ni, D. L. Yu, and Y. W. Du, "Fabrication and magnetic properties of $\mathrm{Co}_{67} \mathrm{Ni}_{33}$ alloy nanowire array," Scripta Materialia, vol. 44, pp. 2291-2295, 2001.

[17] T. Ramchandran and T. K. Namboodhiri, "Potentiostatic evaluation of the corrosion of a Ni-Co base amorphous alloy," Corrosion, vol. 40, no. 2, pp. 73-77, 1984.

[18] M. M. Parente, O. R. Mattos, S. L. Díz, P. L. Neto, and F. J. F. Miranda, "Electrochemical characterization of Ni-P and NiCo-P amorphous alloy deposits obtained by electrodeposition," Journal of Applied Electrochemistry, vol. 31, no. 6, pp. 677-683, 2001.

[19] A. Aledresse and A. Alfantazi, "A study on the corrosion behavior of nanostructured electrodeposited cobalt," Journal of Materials Science, vol. 39, no. 4, pp. 1523-1526, 2004.

[20] S. Pang, T. Zhang, K. Asami, and A. Inoue, "Bulk glassy $\mathrm{Ni}(\mathrm{Co}-) \mathrm{Nb}-\mathrm{Ti}-\mathrm{Zr}$ alloys with high corrosion resistance and high strength," Materials Science and Engineering A, vol. 375-377, no. 1-2, pp. 368-371, 2004. 
[21] I. H. Toor, K. J. Park, and H. Kwon, "Manganese effects on repassivation kinetics and SCC susceptibility of high Mn-N austenitic stainless steel alloys," Journal of the Electrochemical Society, vol. 154, no. 9, pp. C494-C499, 2007.

[22] H. J. Jang, C. J. Park, and H. S. Kwon, "Photoelectrochemical study of the growth of the passive film formed on Fe-20Cr-15Ni in a $\mathrm{pH} 8.5$ buffer solution," Metals and Materials International, vol. 16, 247252 pages, 2010.

[23] H. J. Jang, C. J. Park, and H. S. Kwon, "Photoelectrochemical analysis on the passive film formed on $\mathrm{Ni}$ in $\mathrm{pH} 8.5$ buffer solution," Electrochimica Acta, vol. 50, no. 16-17, pp. 3503-3508, 2005.

[24] A. Aledresse and A. Alfantazi, "A study on the corrosion behavior of nanostructured electrodeposited cobalt," Journal of Materials Science, vol. 39, no. 4, pp. 1523-1526, 2004.

[25] R. Rofagha, R. Langer, A. M. El-Sherik, G. Palumbo, and K. T. Aust, "The corrosion behaviour of nanocrystalline nickel," Scripta Metallurgica et Materiala, vol. 25, no. 12, pp. 2867-2872, 1991.

[26] M. Pourbaix, Atlas of Electrochemical Equilibrium Diagrams in Aqueous Solutions, NACE, Houston, Tex, USA, 1966.

[27] W. A. Badawy, F. M. Al-Kharafi, and J. R. Aaljmi, "Corrosion and passivation behaviour of cobalt in aqueous solutions," Bulletin of Electrochemistry, vol. 16, no. 4, pp. 145-154, 2000. 

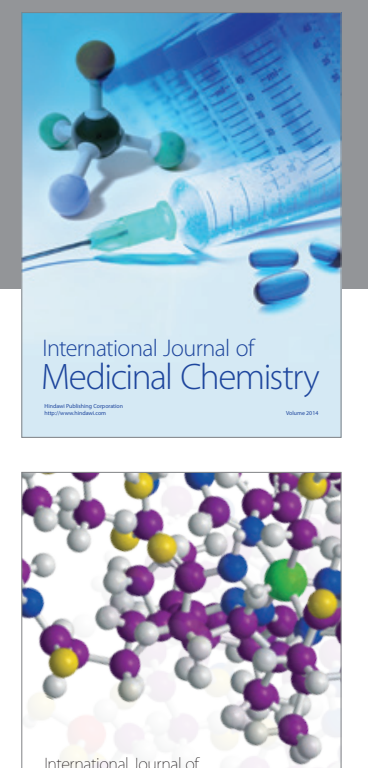

\section{Carbohydrate} Chemistry

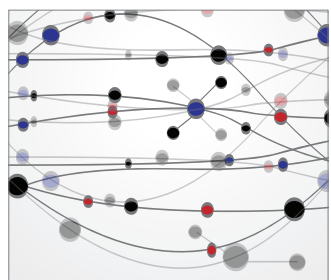

The Scientific World Journal
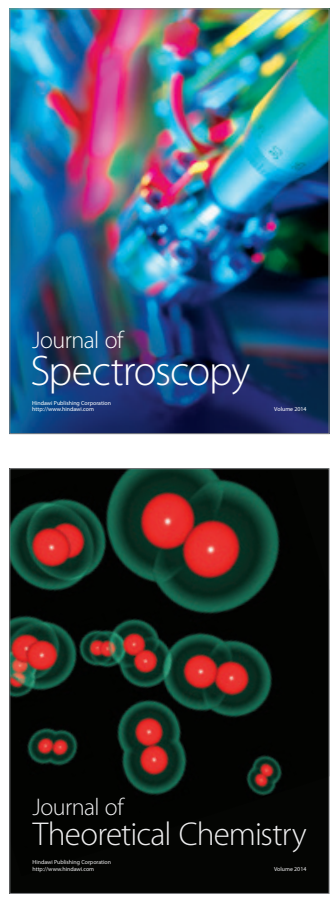
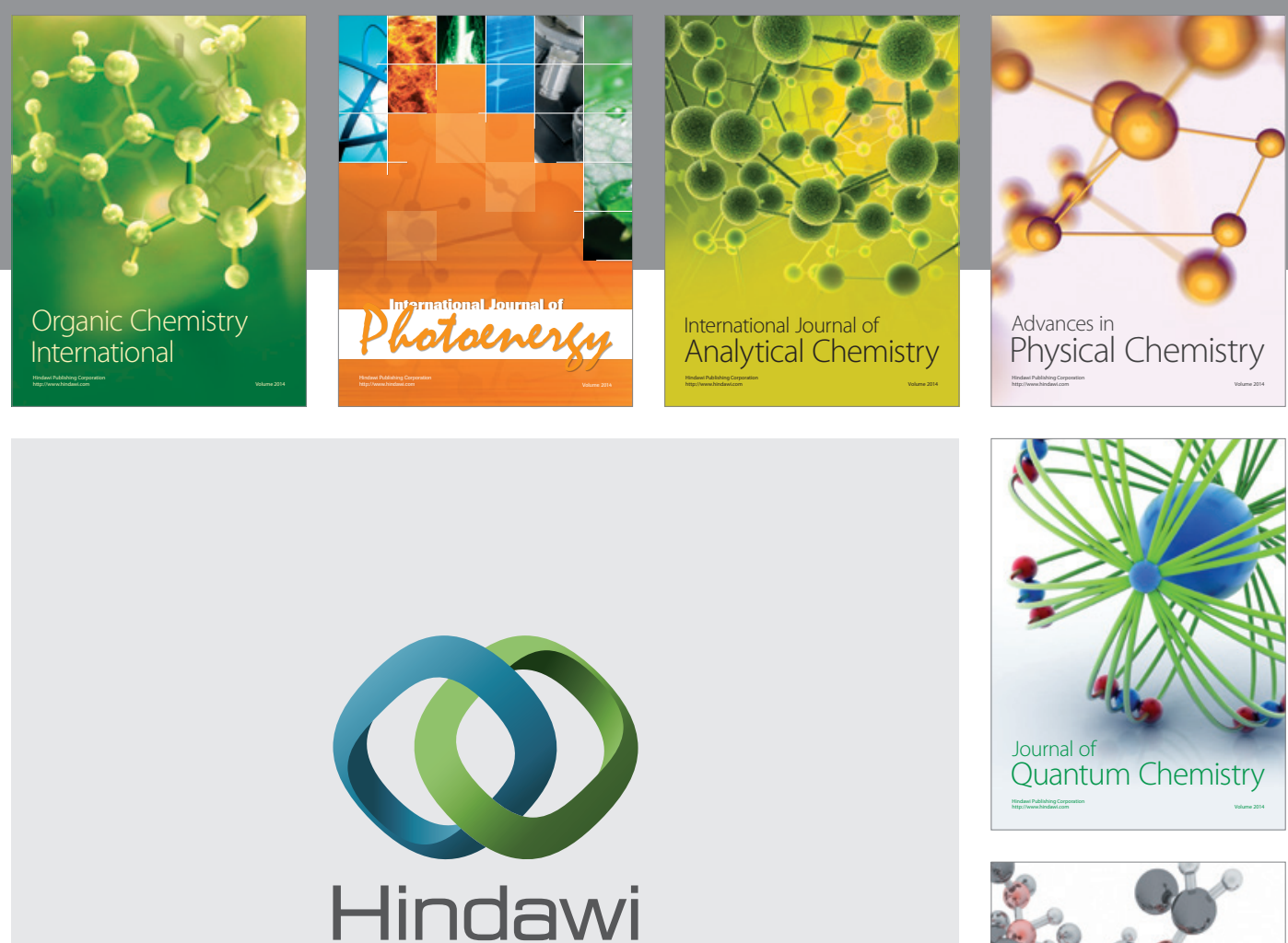

Submit your manuscripts at

http://www.hindawi.com

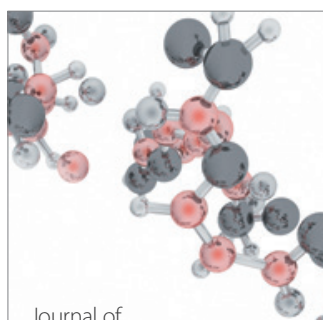

Analytical Methods

in Chemistry

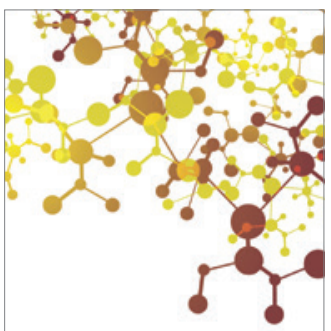

Journal of

Applied Chemistry

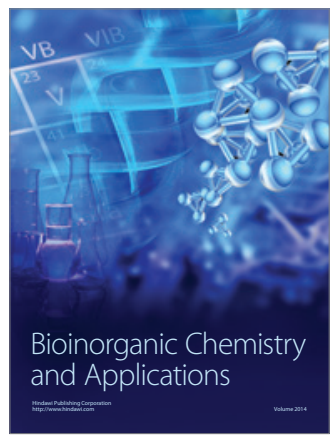

Inorganic Chemistry
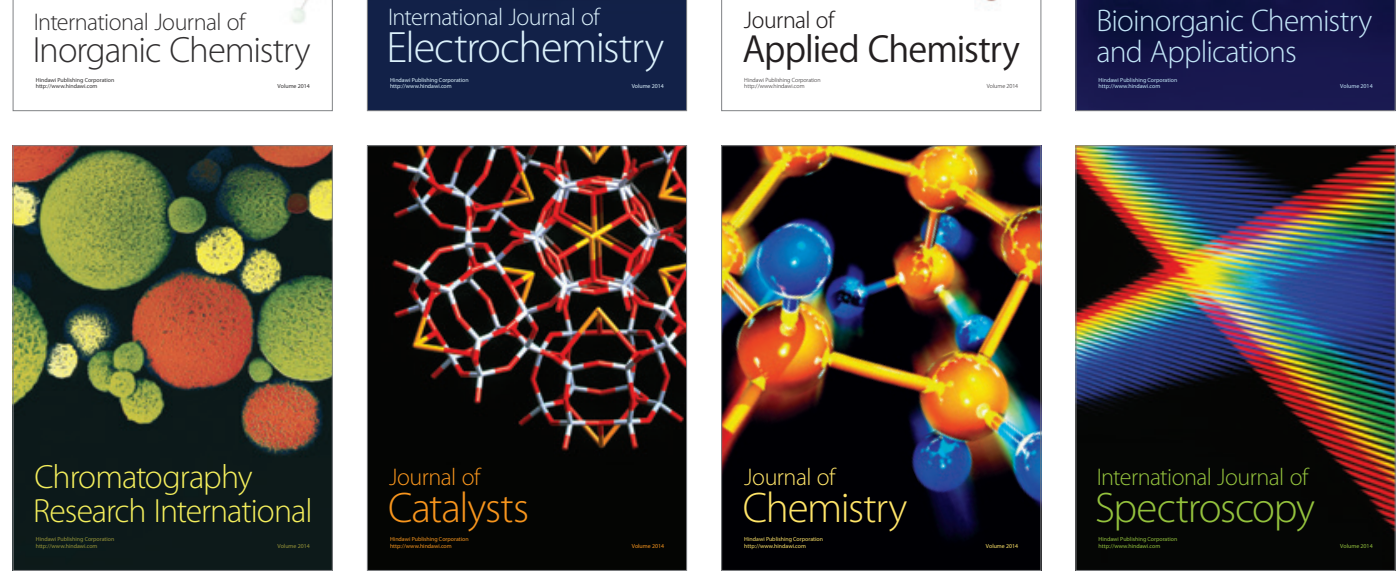